\title{
Identifikasi Tingkat Getaran Gempa Di Kabupaten Sigi Berdasarkan Skenario Shakemap Mw 6,9 Sesar Palu Koro
}

\author{
(Identification of Earthquake Shake Levels in Sigi Regency Based on Mw 6,9 Shakemap \\ Scenario by Palu Koro Fault)
}

\author{
H. Leopatty ${ }^{1)}$, M. N. Rande ${ }^{1)}$, Rustan Efendi ${ }^{2 *}$, I. F. Asyhar ${ }^{1)}$ dan M. Cholidani ${ }^{1)}$ \\ 1) Stasiun Geofisika Palu - BMKG \\ 2) Universitas Tadulako
}

\section{Info}

Article history:

Received: 14 July 2021

Accepted: 30 December 2021

Published: 31 December 2021

\section{Kata kunci:}

Gempabumi,

Shakemap,

Skala MMI

\section{Keywords:}

Earthquake,

Shakemap,

MMI Scale

*) e-mail: rstefendi67@gmail.com

\begin{abstract}
Abstrak.
Kabupaten Sigi merupakan wilayah aktif gempabumi, utamanya bersumber pada aktivitas Sesar Palu Koro. Berdasarkan kejadian gempabumi PASIGALA 28 September 2018 dengan magnitudo 7,4 Mw, tingkat guncangan mencapai VII-VIII MMI di Sigi. Untuk mendukung pembuatan dokumen rencana kontijensi gempabumi di Kabupaten Sigi, digunakan sumber skenario gempa Mw 6,9 yang terjadi di segmen Saluki dengan koordinat $120,01^{0} \mathrm{BT}-1,25^{0} \mathrm{LS}$ di kedalaman $11 \mathrm{~km}$. Prakiraan tingkat guncangan secara umum di Kabupaten Sigi dapat mencapai VI-VIII MMI.
\end{abstract}

\section{Abstract.}

Sigi Regency is an active earthquake region, mainly sourced from the activity of the Palu Koro Fault. Refer to the "PASIGALA" earthquake M 7.4 Mw on September 28th, 2018 with ground shaking intensity reached VII-VIII MMI level in Sigi. As a support data and preparation of an earthquake contingency plan document in Sigi Regency, we proposed the source scenario of the Mw 6.9 earthquake that would be occurred in the Saluki segment with coordinates 120.010 East Longitude - 1,250 South Latitude, with $11 \mathrm{~km}$ depth of focus. In general, the estimated level of ground shaking intensity in Sigi Regency could be at VI-VIII MMI.

\section{PENDAHULUAN}

Indonesia dikenal dengan negara yang memiliki tingkat seismisitas/kegempaan yang tinggi, hal ini disebabkan Indonesia berada di batas pertemuan antar lempeng yaitu lempeng samudera Pasifik, lempeng benua Eurasia dan IndoAustralia serta mikro lempeng Filipina yang sangat aktif bergerak (penulis). Aktivitas dari keempat lempeng tersebut memiliki sejarah dalam pembentukan pulau Sulawesi dan aktivitas kegempaannya. Dari geodinamika tektonik, bidang patahan aktif gempa utama yaitu berada di jalur Subduksi Sulawesi dengan lokasi di bagian Utara sepanjang pesisir, patahan Palu Koro dan Matano. Tepatnya, terdapat sekitar 47 bidang patahan aktif di pulau ini [1]. Melihat dari sejarah kegempaan di Pulau Sulawesi,mendorong para ahli maupun masyarakat untuksadar akan pentingnya upaya pengurangan resikobencana gempabumi dengan cara "Hidup berkualitas ditanah goyang". Hal tersebut dilakukan melalui edukasi hasil identifikasi dan analisa pemetaan: peta risiko gempabumi Sulawesi Tengah. Hasil identifikasi tersebut menjadi salah satu poinpenting dalam upaya mitigasi dan adaptasi sertadorongan agar dari sisi legalitas hadir sebuah payung hukum di wilayah administrasipemerintahan, yaitu sebuah dokumen yang dikenal sebagai dokumen rencana kontijensi gempabumi, yang kemudian dapat dievaluasi serta disahkan dan dapat diperbaharui secara berkala dalam kerangka ilmiah yang benar dan tepat.

Provinsi Sulawesi Tengah merupakan salah satu wilayah Indonesia dengan sejarah kegempaan yang sangat aktif. Hal ini disebabkan karena adanya proses pembentukan tatanan geodinamika tektonik Pulau Sulawesi dari pertemuan 
beberapa lempeng yang sangat kompleks dimana bagian Selatan pulau relatif stabil. Berdasarkan kelompok besar mintakat batuan, Sulawesi terbagi menjadi tiga yaitu busur vulkanik-plutonik Barat Sulawesi, Lajur MetamorfikTengah Sulawesi dan Blok Banggai Sula dan Tukang Besi. Berdasarkan tatanan geologi, disisi Utara didominasi oleh batuan gunung api, disisi Barat oleh batuan gunung api, metamorf dan sedimen dan disisi Timur, umumnya batuan metamorf dan ofiolit.

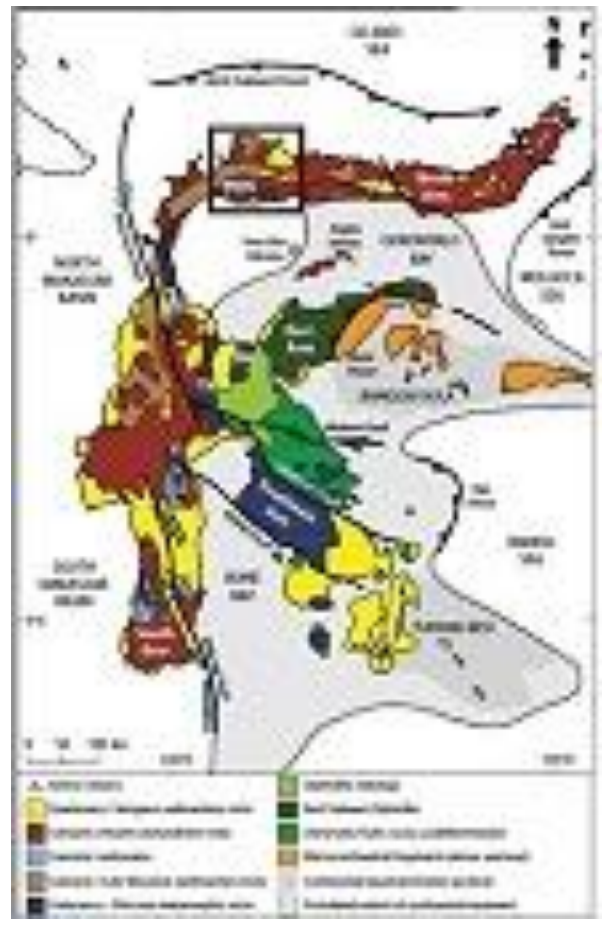

Gambar 1. Geo-tektonik Pulau Sulawesi[2]

Berdasarkan data GPS hasil penelitian tahun 2016, untuk pergerakan lempeng, maka diketahui kecepatan pergerakannya sangat variatif mulai dari 8 hingga 46 $\mathrm{mm} /$ tahun dengan arah gerak dominan ke Barat Laut hingga Utara (Gambar 2).

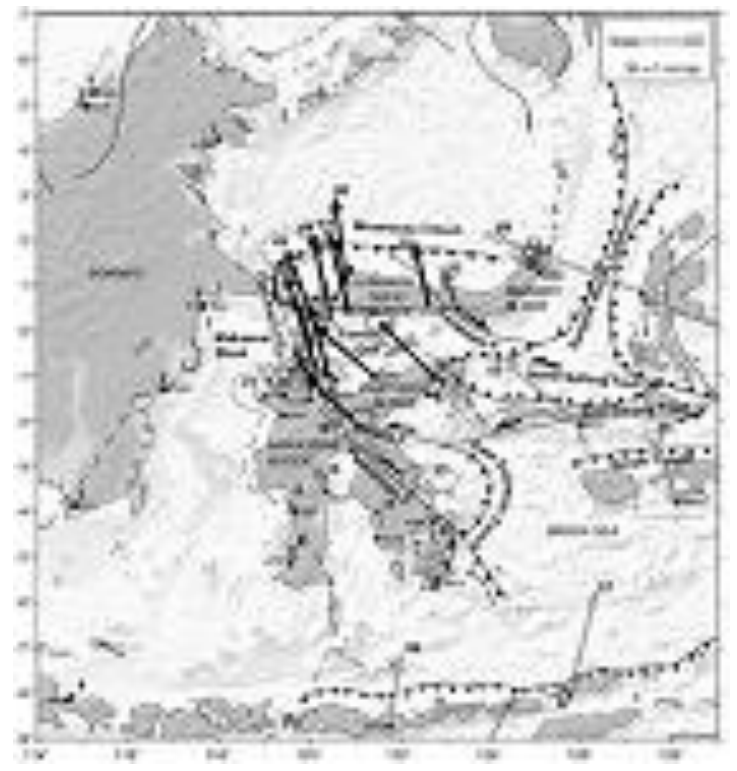

Gambar 2. Peta kecepatan lempeng di Sulawesiłerdasarkan data GPS[3]
Terdapat 47 bidang patahan aktif pemicu gempabumi tektonik yang ada di Sulawesi. Patahan Palu Koro terdiri dari 4 segmen dan patahan Matano terdiri dari 6 segmen, memiliki kecenderungan menghasilkangempa merusak yang sangat luas efek guncangannyadipermukaan dengan proyeksi prakiraan kekuatan tidak melebihi magnitudo 8,0 Sedangkan sumber gempa di jalur subduksi Sulawesi memiliki potensi memicu aktivitas gempa megathrust dengan magnitudo hingga 8,0 [1]. Kegempaan utama di wilayah Sigi bersumber dariaktivitas patahan Palu Koro yang terdiri dari 4segmen. Selain itu, terdapat $\mathrm{P}$ alolo Graben dan patahan aktif lainnya yang berada di luar batasadministrasi pemerintahan Sigi. Sejarah gempa merusakyang melanda Kabupaten Sigi diatas tahun 2000-anialah gempabumi yang terjadi di tahun 2005, 2012, 2018 dan 2020 [4].

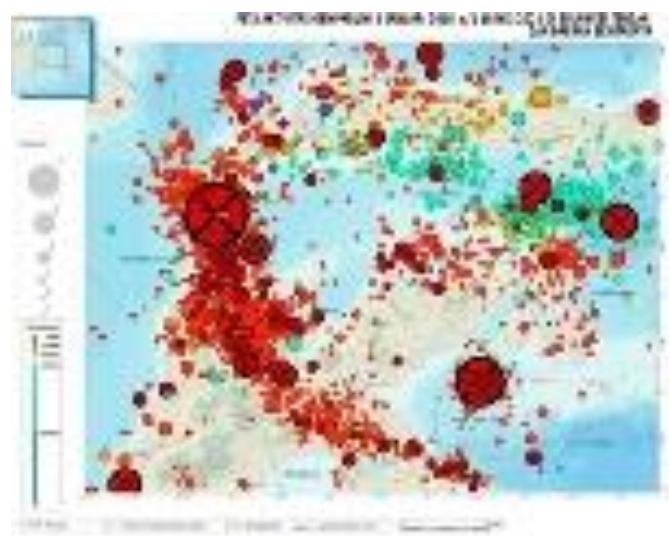

Gambar 3. Peta aktivitas gempabumi di Sulawesi Tengah dan sekitarnya dari tanggal 1 Januari 2018hingga 18 Mei 2021

Dari Gambar 3, terlihat bahwa Kabupaten Sigi berada di atas sumber gempa aktif dengan tipe kedalaman dangkal (didominasi dengan kedalaman gempa berkisar antara 4 hingga $25 \mathrm{~km} \mathrm{[5].} \mathrm{Pemicu} \mathrm{utamanya} \mathrm{ialah} \mathrm{aktivitas} \mathrm{patahan}$ Palu Koro dan Palolo Graben. Dalam hal ini bukan berarti masyarakat tidak dapat tinggal di Kabupaten Sigi, tetapi diharapkan mampu hidup beradaptasi diatas kondisi kegempaan yang aktif. Oleh karena itu, instansi pemerintah terkait dan masyarakat belajar bekerjasama lebih aktif dalam upaya mitigasi dan adaptasi dalam kerangka upaya pengurangan risiko gempabumi, baik melaluikearifan lokal setempat maupun memanfaatkan kemajuan teknologi yang ada.

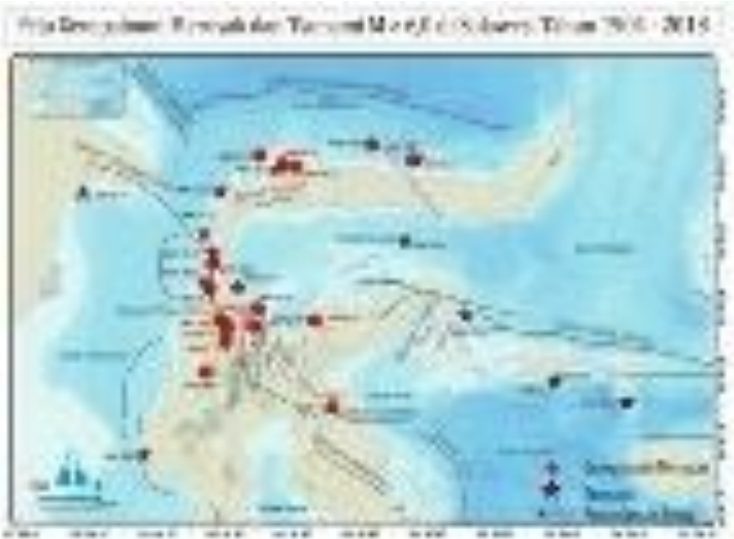

Gambar 4. Peta Gempabumi merusak dan Tsunami di Sulawesi[4] 
Berdasarkan sejarah gempabumi merusak sejak tahun 2000-an hingga kini, maka telah terdapat 3 kali gempabumi dengan kekuatan Mw 5,8 hingga $\mathrm{Mw}$ 7,4. Dari sisi tingkat guncangan gempa disertai dampak kerusakan dan kerugian yang ditimbulkan di Kabupaten Sigi, selain kedelapan gempa tersebut, terdapat dampak gempa patahan Palu Koro tahun 1907, 1909, 1927, dan 1968, serta aktivitas gempa di patahan lainnya pada tahun 1998 dan 2017 (gambar 4).

Pada Tabel 1, tingkat kerusakan akibat gempa dipengaruhi oleh : besar kekuatan disumber gempa $(\mathrm{M})$, kedalaman $(\mathrm{H})$, jarak lokasi ke sumber gempa (D), faktor tapak lokal dan struktur bangunan. Secara garis besar faktor tapak lokal dapat menceritakankecenderungan jenis tanah di permukaan seperti kelas batuan keras (A), batuan (B), batuan lunak dengan variasi tanah padat (C), tanah keras/kaku (D)dan tanah lunak (E) (Gambar 5). Selain itu, faktor amplifikasi atau penguatan gempa dapat terjadi lebihbesar misal antara tanah jenis $\mathrm{E}$ daripada B. Contoh kasus sebuah gempa terjadi, namun di pegunungan sebelah Barat Sigi misal beramplifikasi dengan nilai $\mathrm{X}$ dan di wilayah lembah Sigi bisa jadi $\mathrm{X}+\mathrm{Y}$, dimana $\mathrm{Y}$ $\neq 0$. Pengurangan resiko pada faktor kelima (struktur bangunan) dapat dilakukan melalui rekayasa struktur sesuai dengan standar kode bangunan aman/tahan gempa

Tabel 1. Data kejadian gempabumi merusak di Kabupaten Sigi setelah Tahun 2000-an [4]

\begin{tabular}{|c|c|c|c|c|c|c|c|c|}
\hline No & Tanezal & $\begin{array}{l}\text { Waktu } \\
\text { (WirtaA }\end{array}$ & Lintang & Bujur & Magnitudo & Kedalaman & Keterangan & Ditrasakan \\
\hline 1 & 24/an-2005 4 & 4:10:00 & .1 .030 & 119.990 & 6.2 & ${ }_{11}^{11}$ & $\begin{array}{l}\text { dil darat, } 20 \mathrm{~km} \text { arah tenegerara } \\
\text { Palu Prop, SULTENG }\end{array}$ & 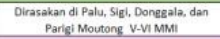 \\
\hline 2 & 18. Aug 201217 & 17:41:50 & -1.300 & 120.040 & 6.2 & 10 & 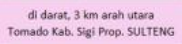 & 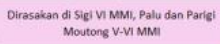 \\
\hline 3 & 28-5ep-2018 1 & 14:59:56 & -0.350 & 119.820 & 5.9 & 10 & $\begin{array}{l}\text { di laut, } 11 \text { Km arah Baratlaut } \\
\text { Alindau Kab .ongeala Prog. } \\
\text { SULTENG }\end{array}$ & 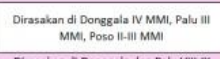 \\
\hline 4 & 28 -5ep-2018 18 & 18:02:43 & -0.190 & 119.830 & 7.4 & 10 & 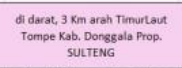 & 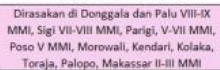 \\
\hline 5 & 28 -5ep-2018 18 & 18:14:21 & 0.000 & 119.830 & 5.8 & 14 & $\begin{array}{l}\text { dil liaut, } 11 \mathrm{~km} \text { arah Bearatlout } \\
\text { Tambu Kob. Dongggale Prop. } \\
\text { SUUTTENG }\end{array}$ & Dirasakan di Donggalis dan Palu V MMI \\
\hline 6 & $28.50-2018$ 18 & 18:16:51 & .0 .800 & 120.010 & 5.8 & 10 & 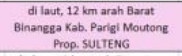 & $\begin{array}{l}\text { Difrasakan di Palu, Sigi, Parigi Moutong V } \\
\text { MML, Donggala IV.V MMI }\end{array}$ \\
\hline 7 & 28 -5ep-2018 18 & 18:25:05 & .0 .980 & 119.990 & 5.7 & 14 & $\begin{array}{l}\text { di diarat, } 8 \mathrm{~km} \text { arah Timurlaut } \\
\text { Bora Kab. Sigi Prop, SUITENG }\end{array}$ & $\begin{array}{l}\text { Dirassakam di Palu dan Sigi M MMI, Parigi } \\
\text { Mouttong dan Dongsgala IV:V MMI }\end{array}$ \\
\hline 8 & 28:Mar-2020 23 & 23:4:17 & 1.720 & 120.140 & 5.8 & 10 & $\begin{array}{l}\text { did darat, } 46 \text { Kn Tengearar Sigl- } \\
\text { SUITENG }\end{array}$ & 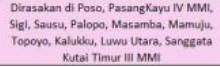 \\
\hline
\end{tabular}

Dari Gambar 5, diketahui bahwa wilayah Sigimemiliki kemungkinan terdampak gempa dengan intensitas tingkat guncangan antar VI hingga IX MMI. Berdasarkan intensitas tingkat guncangan hasil pemodelan shakemap untuk gempabumi merusak tahun 2005 dan 2012, diperoleh informasi bahwa guncangan maksimum mencapai VI MMI dengan degradasi warna kekuningan dan umumnya IV MMI (Gambar 6). Secara geologis, degradasi warna merah umumnya tersusun dari batuan berumur Kuarter berupa alluvium, endapan pantai dan rombokan gunungapi muda yang bersifat lepas dengan peluang teramplifikasi besar (Gambar 5).

Setelah kejadian gempabumi Mw7,4 tanggal 28 September 2018 terjadi, maka dampak yang ditimbulkan secara nyata terjadi di 4 kabupatenkota di Provinsi Sulawesi Tengah, yaitu di Kota Palu, Kabupaten Sigi, Donggala dan Parigi Moutong. Kejadian tersebut dikenal sebagai Bencana Gempabumi Provinsi Sulawesi Tengah Tahun 2018.

Dampak gempabumi secara langsung ialah getaran sangat kuat dengan 3 model guncangan yang ditimbulkan, yaitu guncangan dari gelombang primer, sekunder dan permukaan. Selain itu, terjadi retakan/rekahan di permukaan, tsunami (akibat longsoran tebing di beberapa lokasi berbeda di pesisir Teluk Palu), likuifaksi, tanah longsor, kerusakan infrastruktur serta korban jiwa baik fisik maupun psikis.

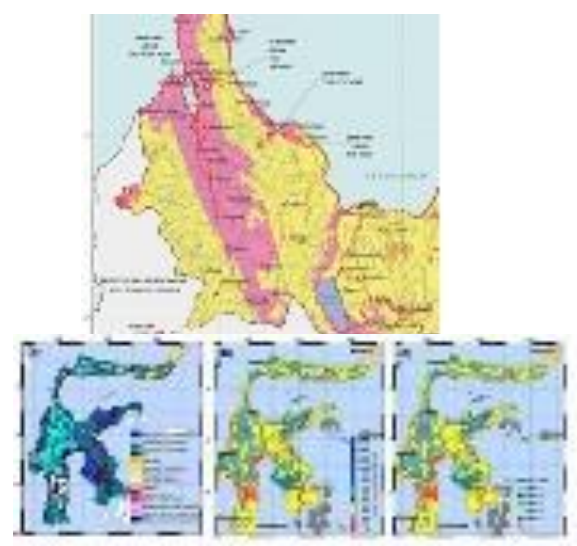

Gambar 5. peta rawan gempa oleh PVMBG tahun 2012 (atas), Peta geomorfologi, Vs30 dan klasifikasitanah berdasarkan NEHRP's [6]
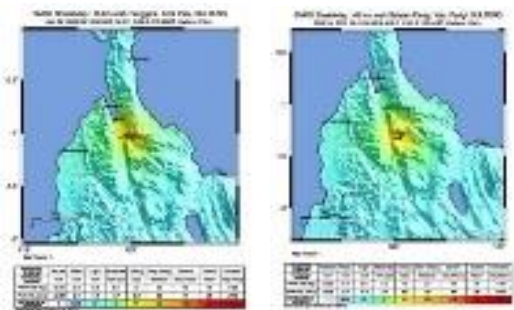

Gambar 6. Peta tingkat guncangan Gempabumi Merusak Sigi Tahun 2005 (kiri) dan 2012 (kanan)

Khusus kejadian likuifaksi di beberapa lokasi, berdasarkan hasil survei dan pengambilan datasampel di lapangan yang dilaksanakan oleh para peneliti, ditemukan bahwa terdapat jebakan air bawah permukaan yang sangat dangkal pada daerah yang mengalami likuifaksi (gambar 7), dengan temuan seperti adanya semburan kecil air yang diikuti material pasiran, atau adanya bangunan yang amblas sebagian merupakan suatu fenomena yang sering dijumpai saat terjadi gempabumi yang besar dengan durasi yang lama. Posisi Gambar 8, masih merupakan prakiraan, dan apabila berada pada posisi di kemiringan lereng tertentu dan kemudian wilayah tersebut mengalami beban gempa beruntun, maka dapat terjadi likuifaksi masif, seperti kasus likuifaksi di Balaroa, Petobo, Jono Oge dan Sibalaya.

Berdasarkan data percepatan tanah maksimum akibat gempa Mw7,4[7] atau penelitian[8] dengan Mw7,5 (USGS) di permukaan, tingkat guncangan di Sigi umumnya berkisar VIVIII MMI, dan percepatan spektra untuk periode 0,2 detik atau perlakuan beban gempa pada gedung 2 lantai berkisar VI-IX MMI. Sedangkan penelitian [9] berkisar diantara VII-VIII MMI dan hasil pemodelan[1] pada gambar 7, percepatan puncak di batuan dasar (SB) untuk probabilitas terlampaui sebesar $2 \%$ dalam 50 tahun diprakirakan berdasarkan analisa dari sebaran gempa yang bersumber dari katalog gempa BMKG dan gempa pada sesar Palu Koro berada pada kisaran nilai 0,7-0,8 g atau setara IX MMI. Berdasarkan data Strong Motion Accelerometer yang terpasang di Bungker Alat Gempabumi BMKG Stasiun Geofisika Palu yang berjarak 80 $\mathrm{km}$ dari sumber episenter gempa Mw7,4, maka diperoleh nilai sebesar 0,34 $\mathrm{g}$ atau berkisar VII-VIII MMI[7] 


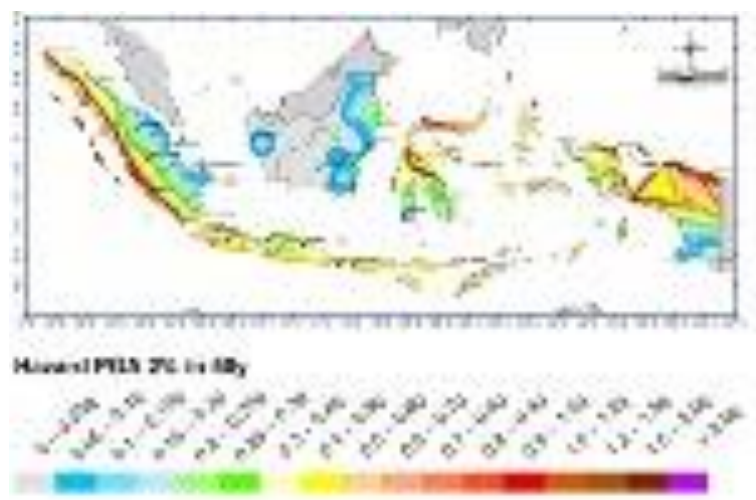

Gambar 7. Peta percepatan puncak di batuan dasar (SB) untuk probabilitas terlampaui sebesar $2 \%$ dalam 50 tahun[1]

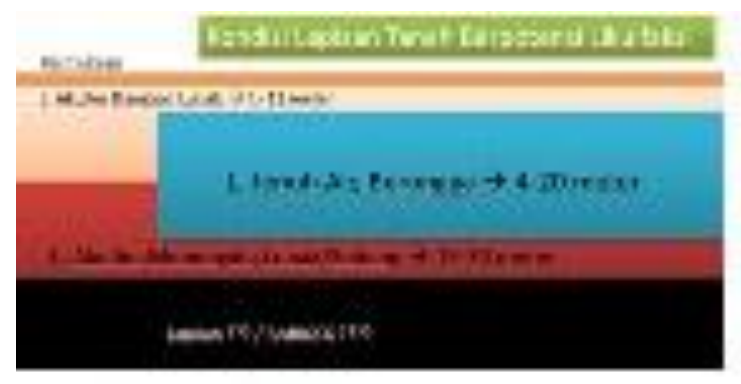

Gambar 8. Gambar ilustrasi sederhana model pelapisan yang umumnya mengalami likufaksi di Palu danSigi, khususnya pada endapan alluvium

Kontijensi ialah suatu kondisi yang diperkirakan akan terjadi, tetapi mungkin juga tidak akan terjadi. Oleh karena ada unsur ketidakpastian, maka diperlukan suatu perencanaan untuk mengurangi dampak yang mungkin terjadi. perencanaan kontijensi ialah proses perencanaan ke depan, dalam keadaan tidak menentu, dimana skenario dan tujuan disetujui, tindakan manajerial dan teknis ditentukan, dan sistem untuk menanggapi kejadian disusun agar dapat mencegah, atau mengatasi secara lebih baik keadaan atau situasi darurat yang dihadapi [10]

\section{BAHAN DAN METODE}

Data yang digunakan dalam penelitian ini adalahdata skenario gempabumi yang diperkirakan dapat terjadi dalam skenario terburuk jika gempa merusak melanda kabupaten Sigi, berdasarkan referensi [1] magnitudo maksimum pada Sesar Palu Koro Segmen Saluki adalah sebesar M6,9 (Gambar 9). Adapun skenario episentrum gempa berdasarkan dua kejadian gempabumi merusak yang terjadi di tahun 2005 dan 2012 (Gambar 6), maka dipilih koordinat : $120,01^{0} \mathrm{BT}$ dan $1,25^{\circ} \mathrm{LS}$ pada kedalaman $11 \mathrm{~km}$. waktu kejadian gempa disesuaikan dengan waktukegiatan rencana kontijensi, yaitu 8 Juni 2021.

Selanjutnya penulis menginput parameter tersebut pada aplikasi Shakemap BMKG untuk mendapatkan peta dampak tingkat guncangan "Shakemap"(Gambar 10). Untuk model pembanding dengan parameter gempa skenario $\mathrm{Mw}$ 6,9, digunakan persamaan empiris ground-motion menurut[11]:

$$
\mathrm{Ln} \mathrm{y}=\mathrm{C} 1+\mathrm{C} 2 \mathrm{M}+\mathrm{C} 3 \ln [\mathrm{R}+\mathrm{C} 4 \exp (\mathrm{C} 5 \mathrm{M})]+\mathrm{C} 6 \mathrm{H}+\mathrm{C} 7(\mathrm{Vs}, 30 / 1130)
$$

dimana y dalam satuan $\mathrm{g}$ unit dan nilai koefisien $\mathrm{C} 1=-5.60, \mathrm{C} 2=1.63, \mathrm{C} 3=-1.70, \mathrm{C} 4=0.51552, \mathrm{C} 5=$
$0.63255, \mathrm{C} 6=0.0075, \mathrm{C} 7=-0.27$ dan $\sigma=0.61$

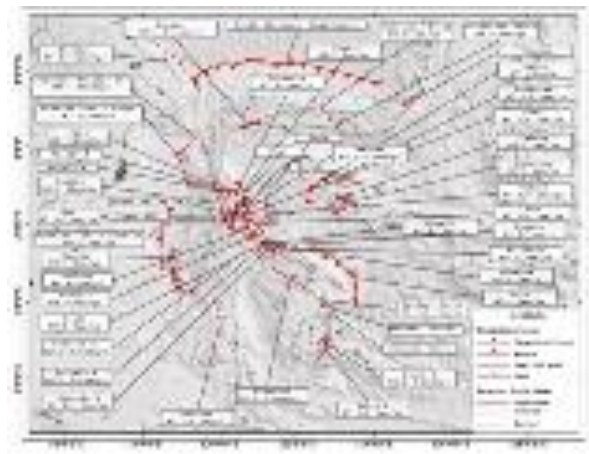

Gambar 9. Peta sumber gempa Indonesia tahun 2017 C3. Wilayah Sulawesi[1]

\section{HASIL DAN PEMBAHASAN}

Setelah dilakukan penginputan dan pengolahan pada aplikasi Shakemap BMKG didapatkan hasil berupa peta tingkat guncangan gempabumi (Gambar 10).

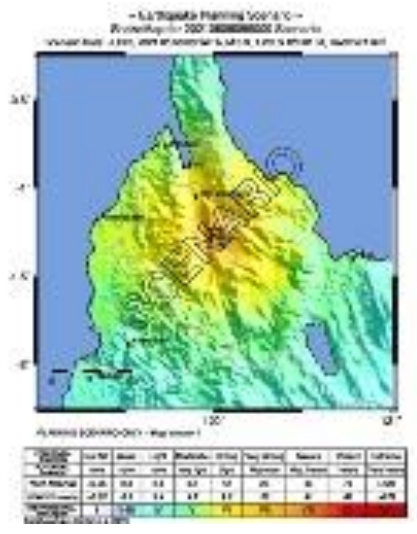

Gambar 10. Peta Skenario dampak guncangan Gempabumi di Kabupaten Sigi dengan Skala MMI

Jika parameter skenario gempa digunakan menggunakan persamaan menurut[11]. maka diperoleh data sebagai berikut:

Tabel 2. Data prakiraan tingkat guncangan skenario gempabumi Mw6,9, kedalaman $11 \mathrm{~km}$ di koordinat $120,01^{0} \mathrm{BT}-1,25^{0} \mathrm{LS}$ menggunakan persamaan (1)

\begin{tabular}{|c|c|c|c|c|}
\hline Lokasi & Lintant & Bujur & Prakiraan Dampak Tingkat Guneangan & larak Sumber Gempe \\
\hline 1 Pakull (Kab, Sigi) & -1.233432 & 119.944686 & VII-VIII MMII & $7 \mathrm{~km}$ arah timur Pakull (Kab. Sigi) \\
\hline 2 Tomado (Kab. Sigi) & 1.330132 & 120.048912 & VIIVVIII MMII & $10 \mathrm{~km}$ arah baratlaut Tomado (Kab, Sigi) \\
\hline 3 Makmur (Kab. . Sigi) & .1 .144439 & 120.059967 & VIIVIIIIMMII & $13 \mathrm{~km}$ arah baratdaya Makmur (Kab, Sigi) \\
\hline 4 Baluase (Kab. Sigi) & -1.198588 & 119.895679 & VIIMMII & $14 \mathrm{~km}$ arah tenggara Baluase (Kab. Sigi) \\
\hline 5 Kamarora (Kab, Sigil) & -1.192500 & 120.132423 & VII MMII & $15 \mathrm{~km}$ arah baratdaya Kamarora $(\mathrm{Kab}$, Sigl| \\
\hline 6 Sibalaya (Kab. Sigi) & -1.144091 & 119.920990 & VIIMMI & $15 \mathrm{~km}$ arah tengegara Sibalaya (Kab. Sigi) \\
\hline 7 Kulawi (Kab. Sigi) & 1.441667 & 119.986764 & VII MMI & $21 \mathrm{~km}$ arah utara Kulawi (Kab. Sigi) \\
\hline 8 Bora (Kab. Sigi) & .046208 & 119.947283 & VIIMMII & $24 \mathrm{~km}$ arah selatan Bora (Kab. Sigi) \\
\hline 9 Kaleke (Kab. Sigi) & -1.033456 & 119.868432 & VIVVIIIMMII & $29 \mathrm{~km}$ arah tengggara Kaleke (Kob. Sigig) \\
\hline 10 Lawua (Kab. Sigl) & -1.611559 & 120.040957 & VIVVIIIMMII & $40 \mathrm{~km}$ arah utara Lawua (Kab, Sigl) \\
\hline 11 Dombu (Kab. Sigl) & -0.967148 & 119.779983 & VIMMII & $41 \mathrm{~km}$ arah tengegara Dombu (Kab. Sigi) \\
\hline 12. Bangearaba (Kab. Sigi) & .1517849 & 119.739458 & VIMMII & $42 \mathrm{~km}$ arah timurlaut Banggaiba (Kab. Sigi) \\
\hline 13 Peana (Kab. Sigi) & 1.767904 & 119.919066 & V.VIMMII & $58 \mathrm{~km}$ arah utara Peana (Kab. Sigi) \\
\hline
\end{tabular}

Berdasarkan shakemap "skenario" gempabumi pada gambar 10 dan Tabel 2, secara umum Kabupaten Sigi diprakirakan terdampak intensitas antara VI-VIII MMI yaitu kerusakan ringan pada bangunan berkonstruksi, kokoh, pada bangunan berkualitas buruk mengalami kerusakan sedangbesar/rubuh. 
Peta dampak guncangan gempa 28 september 2018 yang dirilis oleh BMKG Jakarta pada tahun 2018, memberikan informasi dampak guncangan gempa Mw 7,4. Gambar 11 menunjukkan adanya perbedaan warna peta (kanan dan kiri) di wilayah Kota Palu dan sebagian daerah kabupaten Sigi. Sebelum adanya penambahan parameter berdasarkan laporan masyarakat, intensitas MMI dari gempa tersebut adalah VIIVIII MMI di kabupaten Donggala. Setelah adanya penambahan parameter laporan masyarakat dan survey lapangan BMKG, dilakukan penginputan dan pengolahan kembali dan di dapatkan hasil intensitas dampak tertinggi/terburuk adalah di Kota Palu dan sebagian wilayah kabupatenSigi yaitu VIII - IX MMI. Dampak tersebut berupa kerusakan sedang-berat pada bangunan berkonstruksi kokoh, pergeseran fondasi, adanya rekahan dipermukaan tanah, longsoran hingga likuifaksi.

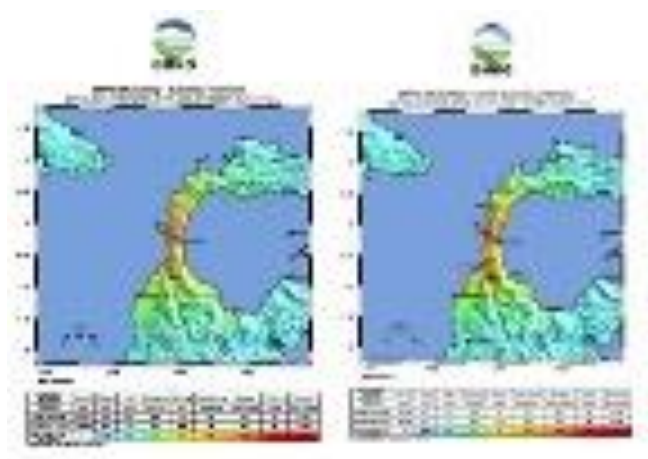

Gambar 11. Peta dampak tingkat guncangan gempabumi Mw7,4 tanggal 28 September 2018 (kiri) dan berdasarkan penambahan laporan Masyarakat [7]

Kasus perbedaan hasil shakemap (Gambar 11) disebabkan sistem pengolahan pada aplikasi Shakemap tidak memasukkan kondisi lokal suatu wilayah, seperti kepadatan penduduk dan pembangunan serta kondisi tanah sekitar. Sehingga pada prinsipnya daerah yang lokasinya dekat denganpusat gempa adalah daerah yang mengalami dampakterburuk dari kejadian gempabumi tersebut. hal ini juga bisa terjadi pada skenario gambar 10, karenaadanya efek tapak lokal pada suatu wilayah. Efek tapak lokal pada masing-masing wilayah akibat gempabumi menjadi perhatian penting dalampembangunan infrastruktur disuatu wilayah. Selain itu, penting adanya upaya pencegahan dan mitigasi, adaptasi hidup dan peningkatan kapasitas masyarakat dalam menghadapi gempabumi. Sehingga, Asas manfaat adanya dokumen rencana kontijensi gempabumi wajib ada di Kabupaten Sigi, dan dilakukan evaluasi dan pembaruan secara berkala. Kerjasama dan koordinasi lintas sektor ditingkatkan. Partisipatif dan tepati komitmen yang disepakati bersama. Bangun rantai peringatan dini. Di sisi lain, berdasarkan Undang-Undang Republik Indonesia No. 31 Tahun 2009, BMKG bekerja 7 x 24 jam, respon positif informasi BMKG terkait Informasi Dini Gempabumi juga sangat diperlukan, guna meredam kepanikan masyarakat dan mencegah berita HOAX.

\section{KESIMPULAN}

Dari pemodelan sumber gempa berdasarkan sejarah dan skenario yang telah dilakukan, dapat disimpulkan bahwa Kabupaten Sigi merupakan wilayah dengan aktivitas gempabumi yang tinggi yang dipicu oleh aktivitas Sesar Palu Koro. Dampak kerusakan dari gempabumi 28 september 2018 pada kabupaten Sigi mencapai VII-VIII MMI. Skenario gempa untuk rencana kontijensigempabumi Kabupaten Sigi ialah gempa di Sesar Palu Koro segmen Saluki. Skenario parameter gempa ialah dikoordinat $120,01^{\circ} \mathrm{BT}-1,25^{\circ} \mathrm{LS}$ dengan kekuatan Mw6,9 di kedalaman $11 \mathrm{~km}$. Prakiraan tingkat guncangan secara umum di Kabupaten Sigi dapat mencapai VI-VIII MMI.

\section{REFERENSI}

[1] PuSGeN, Kajian Gempa Palu Provinsi Sulawesi Tengah 28 September 2018 (M7.4). 2018.

[2]. Advokaat E. L., d., Miocene to Recent Extension in NW Sulawesi, Indonesia. Journal of Asian Earth Sciences, 2017. 17.

[3] Socquet A., d., Microblock Rotations and Fault Coupling in SE Asia Triple Junction (Sulawesi, Indonesia) From GPS and Earthquake Slip Vector Data. Journal of Geophysical Resarch, 2006. 111

[4] Palu, S.G.K.I., Buletin Gempabumi dan Tsunami Sulawesi Tengah Tahun 2018. 2019. Stasiun Geofisika Klas I Palu.

15] Ramdhan M., P., Hypocenter Relocation Analysis of $7.5 \mathrm{Mw}$ Palu and Its Aftershocks: A Preliminary Result. Journal of Physics, 2019. Conference Series 1341082009.

[6.] Cipta, A., dkk, A Probabilistic Seismic Hazard Assesment for Sulawesi, Indonesia. The Geological Society of London. Special Publications, 2016. 441.

[7] BMKG, P., Katalog Gempabumi Signifikan dan Merusak 1821 2018. . BMKG Jakarta, 2019.

[8] Geologi, B., Dibalik Pesona Palu Bencana Melanda Geologi Menata. Kementerian ESDM. Bandung. 2018, Bandung: Badan Geologi Bandung.

[9] R, H.K., Identifikasi Bahaya Gempabumi Dengan Metode Probalistic Seismic Hazard Analysis (PSHA) di Sulawesi Tengah dan Sekitarnya. Jurusan Fisika FMIPA Universitas Brawijaya. Malang, 2019.

[10] Majene, B.B.K., Rencana Kontijensi Menghadapi Ancaman Banjir Kabupaten Majene. Majene, 2012.

[11] Wang, Y. J., Lee, Y. T., Ma, K. F., \& Wu, Y. C. (2016). New Attenuation Relationship for Peak Ground and Pseudo-Spectral Acceleration of Normal-Faulting Earthquakes in Offshore Northeast Taiwan. Terrestrial, Atmospheric \& Oceanic Sciences, 27(1). 